\title{
Research on Impact of Digital Media Art on Animation Design -Take Film and Television Animation Application as Example
}

\author{
Ren Yan ${ }^{1, a}$ \\ ${ }^{1}$ Hebei Vocational Art College, Shijiazhuang, Hebei, 050011
}

Keywords: Digital Media Art, Animation Design, Film and Television Animation

\begin{abstract}
Integration of digital media art in animation design is inevitable. Then the study on the impact of digital media arts on animation design and its future direction has an important significance on the animation design. This paper starts from the concept and development process of digital media art and takes the applications of digital media art in film and television animation design for example to do an in-depth research on the impact of digital media art on animation design, and give a outlook for the future of digital media art. We expected the results of this study can play a practical role in helping the animation design workers, we are also hoping it can play a complementary role in digital media art related theory.
\end{abstract}

\section{Introduction}

With the continuous improvement of the social information process, new media, new technology to achieve between a good contact and integration, and provide some of the more fashionable things, and has the role of promoting social progress. Today, digital technology and new media art has gradually penetrated into a variety of new and old media, which, in touch with people's daily life more and more. Digital Media Arts is being accepted by people familiar with, mainly because of digital media art in animation film and television animation design, especially in the important role of design as well as its enormous impact, both animation and digital media arts have achieved mutual integration, stage common development, digital media arts will have a more important value in the design of future animation.

\section{The Characteristics of Digital Media Art}

The concept of digital media art. The so-called digital media arts, is a modern multi-media technology and modern digital technology, based on the science and art of rational and emotional integration unfolds an art form. We can say that digital media art is science and technology as an effective means to showcase the beauty of art, the art and science of dual attribute determines the digital media art in the field of art and design is currently the most promising branches. Today, digital media arts in film and television animation which get a lot of applications, the development of digital media art also produces film and television animation design innovative role. Meanwhile, the development of film and television animation is constantly calling for more advanced digital media art.

The characteristics of digital media art. According to the concept of digital media art, the digital media art mainly includes the following three features:

First, digital media art scientific and technological nature. Science and technology are the basis of digital media art, creative techniques and forms of digital media art, especially manifestations depend on science and technology.

Second, digital media art has media properties. In modern society, the "digital information" a lot of flooding in people's daily life, work, image after massive processing through digital media art, video, animation anywhere affects people in various social activities.

Third, the digital media arts have fashion. Digital media art itself imprinted with "art art" and "post-modern" and "popular" double feature, is the implementation of those fashion culture. 


\section{The Impact of Digital Media Art on Animation Design}

Impact on design content. Liberalization of time property.Digital media art intervention, breaking the traditional single linear editing mode, replaced by a more flexible way of nonlinear editing. This flexible approach can change the flow of the clip and flow of time, so that the direction of a single, uniform rate of time may have a functional flextime properties appear in any node. In practical applications this way can make the memories, mental activity premonition graphical representation, so that these mental activities more vivid and rich imagery.

Idealization of screen. The application of digital media art has changed the traditional animation of the general reality. It is possible to imagine the scene and people rendered images, it is impossible possible. For example, large-scale war fighting scenes, traditional animation design means it is difficult to achieve, but computer graphics can make real war scenes reproduce; In addition, some imaginary characters and scenes, such as the shape of gods, wonderland scenes, etc. etc., digital media art exhibit can put these things more real, more appealing.

Ideographic of visualization function. The maximum value of the media is the ideographic function, which is to convey the intended meaning. The most essential purpose of animation is the meaning of the expression of the design, so expressive function is designed for the immediate needs of the animation. The development of digital media art, animation design allows the expression of richer content, concerned accepted more quickly. This will directly enhance the animation ideographic function, it is designed ideographic function more direct and accurate.

The diversification of performance style. Since the 20th century, especially in recent years, the rapid development of new media and occupies an important component in people's daily lives. With the development of media and video media websites and other media platforms, some small studios and individuals, original animation and animation works emblematic found their way to development. Freedom of expression and diversity of new media to make up for the shortcomings of traditional cinemas and television animation of unity, diversity of expression means there is a wider audience. In addition, compared to a single digital media art animation designs have broader creative space, making animation more diverse. Animation design is no longer limited to a single two-dimensional animation design, and the impact of digital media art animation design generates develop into three-dimensional animation.

The authenticity of contents convey. The original movie is in the form of two-dimensional space to convey to people's visual system, which is subject to the level of science and technology at the time, said the authenticity of the picture display is not high, it is difficult to bring a personal experience to the audience. The use of digital media art CG technology will be fully integrated space and three-dimensional animation, and animation design applied to them, so that the design of video content, whether it is a scene or character will be more realistic, to give the audience more audio-visual experience. When people watch movies, can feel more realistic, it is even more likely to resonate, this design might be more in line with people's aesthetic demands of contemporary society, so now the animation design increasingly popular. From another point of view, with the development of digital media art, some animation mixed media design products under the new media is increasing, animation design connotation is gradually approaching popular, its content to convey meaning more and more close to the community's daily life, more likely to be accepted by more people.

The personalized and popularization of overall design. Digital animation design reduces the traditional limitations of the design professional, thus reducing the manpower expenditures creation. While Flash and other animation tools to the personal creation provides a convenient, some people realize the dream of an independent producer. Previous animators who must be very professional now than animators growing trend popular and mass. In the information age, the network media can provide a lot of data and materials, plus the designer of civilians, making the design of the product has a strong independence and individuality.

The macro impact on the industry. The continuous development of new media, dissemination and exchange of artistic resources to provide a convenience. More and more digital media art works will be presented for the first time in the media for everyone to enjoy and exchange; more and more 
micro-video, animated short films were produced and released to the new media, you can make direct contact with the public and enjoy. From a sociological point of view, it meets the community most people appreciate the objective needs of the arts, which is also another angle to each behind many professionals in the animation design provides a communication platform for the future lay the foundation for commercial development.

The integration of digital media art, animation film and television industry to industry and an important factor in the rapid development, which is not disputed facts. The integration of digital media art, has prompted for 3D animation, but with the continuous development of digital media art, 3D animation is also moving toward a form of two-dimensional animation CG animation progress. The development of digital media art, is driving forward the animation design industry.

The applications and features of digital media arts in the film and television animation. With the development of digital media art, its application in film and television animation design more and more, has reached a pivotal position. Here a few typical application cases were listed. In 1990, the United States launched a Disney animated film "The Adventures of the Australian rescue hero", which is the world's first fully digital cinema; 1993 Spielberg in "Jurassic Park" were using three-dimensional animation technology to the audience created a vivid image of dinosaurs; 1997's "Titanic" cost \$ 100 million in computer special effects to create distress scene, this is not the film's success to raise awareness of the history of the picture is carried out by means of art picture reproduction, but also to praise the people of St. CG technology to create the visual spectacle of capacity; after that CG effects blockbusters began to emerge in 1999, Disney launched the "Toy Story 2" and the 2002 release of Fox's "Ice Age" is a classic case of CG animated movies; the disaster film 2009 issue of "2012" and the same year by the Cameron broke the box office record of "Avatar" is the rendering of the Seven Wonders of the big scene in general, and on this basis, to join the 3D technology.

Through the above analysis, the current digital media art applications in film and television animation show the following characteristics.

First, more and more widely. In the beginning, digital media art is only applied to the animation scene from pure, then gradually developed into people and animation mixed pure in the scene, and now developed to a scene of pure reality, almost can be said now every film and television animation works digital media art has certain ingredients in it.

Second, the role is growing. Rendering large scenes from the atmosphere to the content of the scene portrayed small; from action figures to smooth precise expressions of the characters. Film and television animation in every aspect because of the addition of digital media art is more accurate, more real, more vivid and more expressive and appealing.

Third, throughout. In film and television animation design, digital media art applications throughout the film and television animation of the whole process. This process is a process of mutual integration of art and technology, is the art of process technology, but also the artistic process of applying technology to achieve. The entire production process in modern film and television animation of the product, from the story idea when you need to add Reflections from digital media arts, and to consider carefully what new scenes and details can be achieved through digital media art, which occurred before the scene and details can be better reproduced through digital media technology. And some of the details in the production process, such as character modeling, behavior, etc., are required to join the digital media arts consideration. Such as matting technology, shooting 3D movies, as well as screenings of media time and props and so on.

\section{The Outlook}

From a scientific point of view the history of human society is bound to the rapid development of science and technology to humanity is to challenge some of the traditional values and beyond, on the development of new media art is also true. Future, digital technology brings timeless and objective material properties in the world, the real world is bound together with the formation of a new form of colorful. At the same time, technological development will bring more wealth creation means, and 
the progress of the human spirit will also bring a broader art space. Generated by the technological development based on artistic behavior, artistic creation has surpassed in history, it broke loose, which have challenged the traditional concept of art of mankind, human or part of the human way of thinking about art appreciation and is bound to happen earthshaking changes. Digital Media Arts will have a certain impact on the development of human society and artistic value in the future. Future development of digital media in film and television animation design will towards the following three aspects:

First, to continue the fusion of art and technology. Technology is the foundation of digital media art, and art is the goal of digital media art, with the further development of digital media art continues fusion of art and technology attributes attribute will be an inevitable trend. In normal social behavior, people produce in their own artistic quality viewing artistic needs, and such demand to achieve by means of science and technology, and finally presented the results of artistic achievement indeed.

Second, the value of creativity will continue to expand. As technology can be replicated, reducing the technical content of artistic creation, such as photography to painting. Technology Properties of digital media art means its design achievement that is not the only work of art, which runs counter to the traditional concept of art. Once the future development of digital media art will be more emphasis on creativity which can not be copied, creativity in digital media art will reflect the value is greater than the value of the traditional art of creative expression.

Third, the popularity deepens. The popularity of digital media art including the creators and users of public popularity would ah. It also includes the process of popularization of its application range. Most current digital media art applications in place or which video products, and our subsistence, means of production, is also among the digitization process, these things will be designed to take into account the growing number of digital media art thinking.

\section{Conclusion}

This paper starts from the concept and development process of digital media art and takes the applications of digital media art in film and television animation design for example to do an in-depth research on the impact of digital media art on animation design, and give a outlook for the future of digital media art.This study suggest that the digital media arts have a positive impact on animation design in varying degrees such as time properties, the scene, express style, content convey and the intended function, etc. In addition, it has a certain role in promoting the entire animation industry. Finally, this paper prospected the development direction of digital media art and it is an effective complement for this article.

\section{References}

[1] H.L.Xing, The characteristics of digital media art design and its impact on traditional art design, Art and Design (theory). 3(2011) 27-28.

[2] S.D.Li, The media and symbol - digital media art theoretical exploration, Beijing Posts and Telecommunications University (Social Science Edition). 2(2011) 1-20.

[3] J.X.Tang, The influence of digital media art on animation art change, Art Education Research. 5(2014) 114-115.

[4] H.Wang, The impact of digital media technology on modern design art, Chinese Media Technology. 8(2012) 31-32. 